\title{
Estudio hematológico en septicemia bacteriana del lactante
}

Publicaciones recientes han insistido en la importancia del hemograma como ayuda diagnóstica de la septicemia bacteriana, tanto del lactante como del recién nacido ${ }^{1-2-3-4-5}$. Se han buscado dentro de este examen los parámetros más significativos ${ }^{3-4}$, como modificaciones de las técnicas clásicas que orienten en este diagnóstico.

El propósito del presente estudio es buscar los hallazgos hematológicos más constantes, durante la evolución clínica de un grupo de pacientes fallecidos, con septicemia bacteriana comprobada anatomopatológicamente. Se correlacionan, además, datos de la hematología con algunos pertinentes clínicos, bacteriológicos y anatomopatológicos.

\section{MATERIAL Y METODOS}

Se tuvo un total de cuarenta y cuatro pacientes con septicemia bacteriana anatomopatológicamente comprobada, cuyas edades fluctuaron entre uno y veintitrés meses, correspondientes a los años 1973 a 1975. El criterio anatomopatológico básico fue la existencia de infiltrados inflamatorios agudos, con predominio de leucocitos polimorfonucleares, en dos o más parénquimas. Se excluyeron las septicemias parasitarias o sospechosas de ser de etiología viral.

Se incluyeron los estudios hematológicos del período en que clínicamente se sospechó la septicemia bacteriana. Revisamos:

a) Cuarenta y cinco series rojas pertenecientes a veintinueve pacientes.

b) Cuarenta series blancas correspondientes a veintiséis pacientes.

- Departamento de Pediatría, Universidad Católica de Chile. Hospital Josefina Martínez de Ferrari.
Dres. Eduardo Talesnik, Myriam Campbell, Rubén Puentes, Martha Pruyas, Hernán Taboada*. T.M. Cartos Lopez*

c) Cuarenta y cinco series plaquetarias pertenecientes a veintinueve pacientes.

Las correlaciones con estudios bacteriológicos se refieren a hemocultivos o mielocultivos pre mortem.

Para clasificar estado nutritivo se utilizó el criterio de $\mathbf{M}$. Sempé (Centro Intemacional de la Infancia, París) considerando valores promedios y desviaciones estándar, para los parámetros peso/edad. De este modo se tuvo:

a) D. I: $\quad-1$ a -2 D.S. (Desviaciones Standard).

b) D. II: -2 a -3 D.S.

c) D. III: Inferior a -3 D.S.

Con el niño de bajo peso de nacimiento se determinó la pérdida en D.S. en relación al propio canal de crecimiento.

Las técnicas del hemograma son las de uso habitual. Se definió trombopenia a recuentos de 150.000 o menos, plaquetas $\times \mathrm{m}^{3}$.

Como valores de leucocitos, usamos de referencia la tabla de Derman ${ }^{6}$, para lactantes entre cuatro semanas y dos años. Esta se expresa en cifras absolutas $\left(\times \mathrm{mm}^{3}\right)$.

Tabla 1

SEPTICEMIA BACTERIANA

Valores normales de leucocitos (Derman)

\begin{tabular}{lrrr}
\hline & Mínimo & Promedio & Máximo \\
\cline { 2 - 4 } $\begin{array}{l}\text { Leucocitos } \\
\begin{array}{c}\text { Neutrófilos } \\
(30 \text { a } 35 \%)\end{array}\end{array}$ & 1.000 & 11.000 & 18.000 \\
$\begin{array}{c}\text { Linfocitos } \\
(40 \text { a } 60 \%)\end{array}$ & 2.500 & 7.800 & 9.000 \\
$\begin{array}{c}\text { Monocitos } \\
(1 \text { a } 10 \%)\end{array}$ & 50 & 600 & 1.000 \\
$\begin{array}{c}\text { Eosinofilos } \\
(1 \text { a 3\%) }\end{array}$ & 40 & 300 & 800 \\
\hline
\end{tabular}


El porcentaje de baciliformes aceptado como normal es hasta de un $6 \%$ del total de leucoci$\operatorname{tos}^{19}$.

\section{RESULTADOS}

\section{SERIE RojA}

La tabla 2 nos muestra la distribución, según hematocrito.

\section{Tabla 2}

SEPTICEMIA BACTERIANA

Distribución por hematocrito

\begin{tabular}{lrr}
\hline Hematocrito & $N^{*}$ Series Rojas & Porcentaje \\
\hline$<20 \%$ & 0 & $0,0 \%$ \\
20 a $25 \%$ & 6 & $13,4 \%$ \\
26 a $30 \%$ & 15 & $33,3 \%$ \\
30 a $50 \%$ & 22 & $48,8 \%$ \\
$>50 \%$ & 2 & $4,5 \%$ \\
\hline Total & 45 & $100,0 \%$ \\
\hline
\end{tabular}

Los hematocritos superiores a $50 \%$ corresponden, uno a un lactante menor de 1 mes 18 días y el otro a un paciente, que al momento de tomarlo, el referido examen presentaba signos clínicos de deshidratación.

Se encontró al frotis presencia de crenocitos y/o esquistocitos en el $75 \%$ de las Series Rojas. Hipocromía o hipercromía y microcitosis en un $20 \%$, correspondiendo todas a lactantes mayores de 6 meses. Macrocitos y/o megalocitos en el $15 \%$ de las Series Rojas.

\section{Serie Plaquetaria}

Trombopenia $(150.000$ a menos, plaquetas $\times \mathrm{mm}^{3}$ ) hubo en 12 , de un total de 45 recuentos, lo que constituye un $26,6 \%$ de éstos. Durante su evolución clínica 10 de los 29 pacientes con recuentos plaquetarios presentaron trombopenia $(34,7 \%)$.

La totalidad de las trombopenias fueron con cifras bajo las 50.000 plaquetas $\times \mathrm{mm}^{3}$. En uno de los recuentos estuvieron ausentes al frotis.

La tabla 3 nos señala la distribución por edad de los pacientes con trombopenia, en relación a la distribución por edad del total de pacientes con recuentos plaquetarios.
Tabla 3

SEPTICEMIA BACTERIANA

Distribución por edad $y$ trombopenia

\begin{tabular}{lcc}
\hline Edad & Pacientes & $\begin{array}{c}\text { Pacientes con } \\
\text { trombopenia } \\
(150.000 \mathrm{pla}- \\
\left.\text { quetas } / \mathrm{mm}^{3}\right)\end{array}$ \\
\hline 1 mes a 2 meses 29 dias & 10 & 6 \\
3 meses a 5 meses 29 dias & 9 & 1 \\
6 meses a 8 meses 29 dias & 7 & 2 \\
9 meses a 11 meses 29 días & 1 & 1 \\
12 meses a 24 meses & 2 & 0 \\
\cline { 2 - 3 } Total & 29 & 10 \\
\hline
\end{tabular}

Así, un $60 \%$ de las trombopenias se presentó en menores de 3 meses, en tanto que este grupo etario constituye un $36,5 \%$ del total de pacientes con recuentos plaquetarios.

La distribución por estado nutritivo en los pacientes con trombopenia fue semejante a la de aquellos que no la presentaron.

De los 29 pacientes en que se practicaron recuentos plaquetarios, se tuvo durante la evolución clínica hemocultivos $\mathrm{y} / \mathrm{o}$ mielocultivos en 20 de ellos, pesquisándose en 12 de los casos cultivos positivos. Los 10 pacientes que cursaron con trombopenia, tuvieron hemocultivos y/o mielocultivos, durante su estudio, lográndose identificar germen en 7 casos. La tabla 4 nos resume la distribución por germen, según técnica de Gram, en el total de pacientes con cultivo positivo y en el grupo con cultivo positivo y trombopenia.

Tabla 4

SEPTICEMIA BACTERIANA

Trombopenia y germen causal de la septicemia (tinción de Gram)

\begin{tabular}{lcc} 
Tipo de germen & $\begin{array}{c}\text { Pacientes con } \\
\text { cultivos positivos }\end{array}$ & $\begin{array}{c}\text { Pacientescon } \\
\text { cultivos positivos } \\
\text { y trombopenia }\end{array}$ \\
\hline Gram (+) & 4 & 1 \\
Gram (-) & 8 & 6 \\
\hline Total & 12 & 7 \\
\hline
\end{tabular}

De los 10 pacientes con trombopenia, uno tuvo hallazgos anatomopatológicos, compatibles con coagulación intravascular diseminada (de predominio renal).

Cabe destacar que cuatro de los diez pacientes con trombopenia recibieron heparina durante las últimas 14 horas de vida $(1 \mathrm{mgr} / \mathrm{Kg} / \mathrm{do}-$ 
sis). En este grupo se incluye al paciente, con hallazgos anatomopatológicos de coagulación int ravascular diseminada.

\section{Serie Blanca}

La tabla 5 nos muestra la distribución por número de leucocitos en nuestra casuística.

Tabla 5

SEPTICEMIA BACTERIANA

Distribución por número de leucocitos

\begin{tabular}{ccc}
\hline Letucoctos $\times \mathrm{mm}^{3}$ & $\begin{array}{c}\text { Númers de } \\
\text { recuentos }\end{array}$ & Porcentaje \\
\hline$<4.000$ & 0 & $0,0 \%$ \\
4.000 a 7.999 & 7 & $17,5 \%$ \\
8.000 a 11.999 & 9 & $22,5 \%$ \\
12.000 a 17.999 & 7 & $17,5 \%$ \\
$>18.000$ & 17 & $42,5 \%$ \\
Total & 40 & $100,0 \%$ \\
\hline
\end{tabular}

Los pacientes con leucocitosis sobre 18.000 se distribuyeron en cuanto a edad y estado nutritivo en igual forma que el total de pacientes con estudio de Serie Blanca.

La tabla 6 nos resume la distribución según número absoluto de neut rófilos.

Tabla 6

SEPTKEMIA BACTERIANA

Distritución por númeno de neutrófitos

\begin{tabular}{lcc}
\hline Veutrófilo $\times \mathrm{mm}^{2}$ & $\begin{array}{c}\text { Vúmero de } \\
\text { recuentos }\end{array}$ & Porcentaje \\
\hline$<1.000$ & 0 & $0,0 \%$ \\
1.000 a 3.799 & 7 & $17,5 \%$ \\
3.800 a 8.999 & 18 & $45,0 \%$ \\
$>9.000$ & 15 & $37.5 \%$ \\
\hline Total & 40 & $100,0 \%$ \\
\hline
\end{tabular}

Granulación tóxica en los neutrófilos se encontró en el 55,0\% de las Series Blancas. Neutrófilos vacuolados en un $17,5 \%$ de éstas.

La distribución por número de linfocitos nos reveló que sólo en un $2,5 \%$ de los recuentos había linfopenia severa, bajo 1.000 linfocitos $\times$ $\mathrm{mm}^{3}$. Linfopenia moderada $(1.000 \quad$ a 2.500 linfocitos $\times \mathrm{mm}^{3}$ ) en un $22,5 \%$ de los recuentos. Un $80 \%$ de las linfopenias se pesquisaron en pacientes con desnutrición de $Z^{\circ}$ y $\mathfrak{F}^{\prime \prime}$ grado (D. Il y D. III). Este grupo de pacientes (D.
II y D. III) constituyen un $57,5 \%$ del total, con estudio de Serie Blanca.

Linfocitosis sobre $18.000 \times \mathrm{mm}^{3}$ hubo en un $15 \%$ de los recuentos. Linfocitos atípicos y linfocitos hiperbasófilos en un 12,5 y $10 \%$, respectivamente.

La tabla 7 nos señala la distribución por número absoluto de monocitos.

Tabla 7

SEPTICEMIA BAC:TERIANA

Distribución por número de monocitos

\begin{tabular}{lcc}
\hline Monocitos $\times \mathrm{mm}^{3}$ & $\begin{array}{c}\text { Número de } \\
\text { recuentos }\end{array}$ & Porcentaje \\
\hline$<1.000$ & 13 & $32,5 \%$ \\
1.000 a 1.999 & 12 & $30,0 \%$ \\
2.000 a 2.999 & 5 & $12,5 \%$ \\
3.000 a 3.999 & 7 & $17,5 \%$ \\
$>4.000$ & 3 & $7,5 \%$ \\
Total & 40 & $100,0 \%$ \\
\hline
\end{tabular}

Así, monocitosis (sobre 1.000 monocitos $\times$ $\mathrm{mm}^{3}$ ) se nos presentó en un $67,5 \%$ de los recuentos. Del total de monocitosis un $62,5 \%$ tiene recuentos mayores a $2.000 \times \mathrm{mm}^{3}$. Un $76,9 \%$ de los pacientes con estudio de Serie Blanca, tuvo. durante su evolución, recuento absoluto de monocitos sobre $1.000 \times \mathrm{mm}^{3}$.

Monocitos vacuolados en un $15 \%$ de los recuentos y linfomonocitos en un $5 \%$ de éstos.

No hubo diferencias en cuanto a distribución por edad, ni por estado nutritivo entre el grupo con monocitosis (sobre 1.000 monocitos $\times \mathrm{mm}^{3}$ ) y el total con examen de Serie Blanca.

Baciliformes, sobre $500 \times \mathrm{mm}^{3}$, se pesquisó en un $55 \%$ de los recuentos, en tanto que ausencia de baciliformes la obtuvimos en un $22,5 \%$ de éstos.

Se tuvo hemocultivos $y / o$ mielocultivos en 18 pacientes de los con examen de Serie Blanca, lográndose cultivos positivos en 11 de ellos. Gérmenes Gram ( + ) hubo en 3 casos y Gram (-) en 8. Esta misma relación se mantuvo en los distintos grupos que presentaron las alteraciones descritas, en cuanto a número, de los diversos elementos de la Serie Blanca.

La tabla 10 es un resumen de los más importantes hallazgos de la Serie Blanca. 
Tabla 8

SEPTICEMIA BACTERIANA

Resumen de hallazgos de la Serie Blanca

\begin{tabular}{|c|c|c|}
\hline . & $\begin{array}{c}\text { Porcentaje de } \\
\text { recuentos }\end{array}$ & $\begin{array}{c}\text { Porcentaje } \\
\text { pacientes }\end{array}$ \\
\hline $\begin{array}{l}\text { Monocitosis } \\
\qquad\left(>1.000 \times \mathrm{mm}^{3}\right)\end{array}$ & $67,5 \%$ & $76,9 \%$ \\
\hline $\begin{array}{l}\text { Baciliformes } \\
\qquad\left(>500 \times \mathrm{mm}^{3}\right)\end{array}$ & $55.0 \%$ & $80,7 \%$ \\
\hline $\begin{array}{l}\text { Granulación tóxica } \\
\text { neutrófilos }\end{array}$ & $55,0 \%$ & $73,8 \%$ \\
\hline $\begin{array}{l}\text { Leucocitosis } \\
\qquad\left(>18.000 \times \mathrm{mm}^{3}\right)\end{array}$ & $42.5 \%$ & $50,0 \%$ \\
\hline $\begin{array}{l}\text { Neutrofilia } \\
\qquad\left(>9.000 \times \mathrm{mm}^{3}\right)\end{array}$ & $37,5 \%$ & $50,0 \%$ \\
\hline $\begin{array}{l}\text { Linfopenia } \\
\qquad\left(<2.5(4) \times \mathrm{mm}^{3}\right)\end{array}$ & $25,0 \%$ & $38,5 \%$ \\
\hline Ausencia baciliformes & $22,5 \%$ & $29,5 \%$ \\
\hline Neutrófilos vacuolados & $17,5 \%$ & $19,2 \%$ \\
\hline Monocitos vacuolados & $15,0 \%$ & $19.2 \%$ \\
\hline $\begin{array}{l}\text { Linforitosis } \\
\qquad\left(>13.000 \times \mathrm{mm}^{3}\right)\end{array}$ & $15,0 \%$ & $15.4 \%$ \\
\hline
\end{tabular}

\section{DISCUSION}

Los hallazgos de la Serie Roja son concordantes con los de la literatura ${ }^{7-8-9}$. La anemia es preferentemente normocítica y normocrómica, su magnitud de leve a moderada. Los signos de hemólisis son preponderantes, este mecanismo y la detención de la maduración a nivel medular, con los básicos involucrados. Otros tipos de anemia asociados a infección son de menor relevancia ${ }^{8}$.

La trombopenia se presentó en un tercio de nuestra casuística. La coagulación intravascular diseminada (CID) se ha invocado como causa de trombopenia en septicemia bacte-

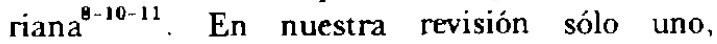
de diez pacientes con trombopenia, tuvo hallazgos anatomopatológicos de CID. Si bien es cierto que en los demás casos ésta no se puede descartar en forma absoluta, dado que la CID puede seguir un curso subagudo, demorando de días a semanas en su instalación y el síndrome completo variar considerablemente en su desarrollo, intensidad y duración ${ }^{11}$, de tal modo que no tendriamos los hallazgos anatomopatológicos habituales, con la formación de trombos de fibrina a nivel de la microcirculación de parénquimas como rin̄ón, encéfalo, hígado, etc., con necrosis o hemorragias de distinta extensión. ${ }^{12}$ Por otro lado, se han invocado me- canismos distintos a la CII) para explicar la trombopenia en septicemia bacteriana. Así, experimentalmente se ha determinado, en conejos, trombopenia mediante la administración de endotoxinas, sin que este efecto sea prevenido por el uso de heparina, planteándose que sean las endotoxinas las responsables de la plaquetopenia, sin que hubiesen otros mecanismos agregados. ${ }^{13}$. Se determinaría una disminución de sobrevida de la plaqueta a lo que se agrega un a limitada capacidad de reserva. ${ }^{5}$

Dos recientes estudios clínicos - sólo en algunos casos de trombopenia en septicemia bacteriana- logran demostrar por métodos de laboratorio $\mathrm{CID}^{1-5}$ Corrigan, ${ }^{1-}$ en 26 pacientes con septicemia bacterianas comprobada y plaquetopenia, determina en 7 de ellos hallazgos de laboratorio compatibles con CID (trombopenia, concentraciones bajas de factor II, V, VIII y fibrinógeno y FSP positivo en suero. En otros 10 pacientes la CID era sólo sospechosa (alteraciones semejantes a las anteriores, pero con factor vili normal o aumentado. Así, sólo se ha podido certificar CID por medio de laboratorio o como en nuestro trabajo a la anatomía patológica, en algunos casos de trombopenia en septicemia bacteriana. Su real incidencia en estos cuadros se desconoce y se postulan mecanismos diferentes a la CID para explicarla.

Las cifras de plaquetas bajo $50.000 \times \mathrm{mm}^{\mathrm{s}}$, en todas las trombopenias pesquisadas se explican por la acción no controlada del mecanismo causal.

Las trombopenias se nos presentaron preferentemente en las septicemias bacterianas del menor de tres meses. Encontramos predominio de Gram (-) en este grupo etario, factor que sería importante en esta distribución. Asimismo, hubo mayor proporción de etiología Gram (-) en los pacientes con trombopenia. La producción de endotoxinas, frecuente en los Gram ( - ) y éstas a través de los mecanismos postulados (CID o acción directa) originarían la plaquetopenia.

Diversos autores han buscado, en el estudio de la Serie Blanca, parámetros en el recuento diferencial, en cifras absolutas, de algunos de sus elementos o en la presencia de determinadas alteraciones morfológicas en los leucocitos, índices que tuvieran valor predictivo en cuanto al diagnóstico de septicemia bacteriana ${ }^{3.4}$. Técnicas como la del buffy-coat han sido mo- 
dificaciones de las clásicas en busca de una mayor precisión diagnóstica ${ }^{2}$.

Nuestra casuística está constituida por septicemias bacterianas comprobadas, de modo que la tabla 8 , en este trabajo, la interpretamos como de orientación diagnóstica, en cuanto a la existencia de la combinación de las alteraciones de la Serie Blanca allí resumidas.

Dos recientes trabajos nacionales hacen hincapié en el monocito tanto en su función inmunológica como su presencia en patologías pediátricas de diverso origen. Confirmamos, la monocitosis en septicemia bacteriana del lactante, siendo de alta frecuencia en nuestro material $^{14 \cdot 15}$. (Una completa revisión de los mecanismos de monocitosis en infecciones bacterianas del lactante la encontramos en la referencia ${ }^{14}$.

Destacamos, la mayor incidencia de linfopenia en pacientes D. II y D. III. Se ha descrito linfopenia en pacientes fallecidos con desnutrición proteico-calórica. En este mismo tipo de desnutridos se ha medido la capacidad proliferativa en linfocitos y se la ha encontrado disminuida $^{16}$. En nuestra casuística, la forma de la desnutrición es la calórico-proteica. En esta, igualmente se ha medido in vitro la capacidad proliferativa de linfocitos, mediante transformación blástica estimulada con fitohemaglutinina, y se han encontrado valores de transformación normales ${ }^{17-18}$.

\section{RESUMEN}

Se revisaron, retrospectivamente, los estudios hematológicos de cuarenta y cuatro lactantes fallecidos, con septicemia bacteriana corroborada a la anatomía patológica, pertenecientes al periodo comprendido entre 1973 y 1975.

Anemia de leve a moderada en un $46,7 \%$ de los recuentos, con signos de hemólisis en un $75 \%$ de los frotis.

Pacientes que cursaron con trombopenia fueron, en una mayor proporción, menores de tres meses y con etiología de la septicemia por Gram ( - ). En uno de diez pacientes con trombopenia se pesquisó a la anatomía patológica, hallazgos compatibles con coagulación intravascular diseminada. Se postula como un mecanismo, distinto al anterior, para explicar la trombopenia en septicemia bacteriana, a la acción directa de las endotoxinas bacterianas sobre las plaquetas.

En la Serie Blanca se configuró una tabla de las alteraciones a la morfología y en el número de los leucocitos y sus formas. La referida tabla se interpreta como de orientación diagnóstica en septicemia bacteriana del lactante, en cuanto a la pesquisa de la combinación de las alteraciones allí expresadas. Confirmamos la monocitosis como de alta frecuencia en estos cuadros, en nuestra casuística presente en el $76,9 \%$ de los pacientes. Las linfopenias se nos presentaron, con una mayor incidencia, en pacientes D. II y D. III

\section{REFERENCIAS}

1 Corrigan, J.J. Pediat. 85, 219, 1974.

2 Faden, H. J. Pediat. 88, 1032, June 1976.

S Kennedy Todd, J. Am. J. Dis. Child. 127:810-816, June 1974.

1 Gellis, S. Year book of Pediatrics. Pag. 268-270; Years book Medical Publishers Inc., 1976.

b Zipursky, A. and col. Pediatrics. $57(6)$ 839-853, June 1976.

- Derman, H. Hematological Normas in Infancy, Pag 376. The Clinical Pathology of Infancy. Charles C. Thomas, 1967

Mutus, W.J. Med. Clin. North. Am. 50 (6) 1703, November 1966.

8 Murdock, J. MC. O.; Smith, C.C. Clinics. Haemat. $1,619,1972$.

9 Mengel, $C h$ and col. Archivos of Intemal Med. 119, 287, March 1967.

10 Ditney, $R$. Seminars. Hemat. 1, 112, January 1971

"Cyr, D.; Mehta, V. Med. Clin. North Am. 53, 301, March 1969.

12 Han $S_{c o b} K i m$ and col. Am. J. Clinics Pathology. 66, 31-39, 1976.

13 Corrigan, J. Jr. Proceeding of the Society for Experimental Biology and Medicine. 136(1), 124, January 1971

14 Donoso, J.M. y col Rev. Chile. Pediat. 46, 509-519. 1975.

is Taboada, H. Rev. Chile. Pediat. (en prensa)

16 Smythe, P.M. and col. Lancet. 2:939, 1971.

17 Schlesinger, L.; Stoket, A. Rev. Chile. Pediat. 44. 455-462. 1973.

18 López, $V$. and col. Pediatric Res. 6:779, 1972.

19 Mathy, K. A.; Koepke, J.A. Am. J. Clinical Pathology 61, 947-958, June 1974 